American Journal of Pharmacology and Toxicology 7 (2): 73-80, 2012

ISSN 1557-4962

(C) 2012 Science Publications

\title{
Gastroprotective Effect and Safety Assessment of Zanthoxylum Zanthoxyloides (Lam) Waterm Root Bark Extract
}

\author{
${ }^{1}$ Alex Boye, ${ }^{2}$ George Asumeng Koffuor, ${ }^{3}$ Johnson Nyarko Boampong, \\ ${ }^{4}$ Patrick Amoateng, ${ }^{2}$ Elvis Ofori Ameyaw, ${ }^{1}$ Ernest Owusu Ansah, ${ }^{1}$ Gabriel Manu Addai, \\ ${ }^{1}$ Cecilia Konama Adjei, ${ }^{5}$ Justice Addo and ${ }^{1}$ Dennis Korbla Amego Penu \\ ${ }^{1}$ Department of Medical Laboratory, Faculty of Science, \\ University of Cape Coast, Cape Coast, Ghana \\ ${ }^{2}$ Department of Pharmacology, \\ Faculty of Pharmacy and Pharmaceutical Sciences, \\ Kwame Nkrumah University of Science and Technology, Kumasi, Ghana \\ ${ }^{3}$ Department of Human Biology, School of Biological Sciences, \\ University of Cape Coast, Cape Coast, Ghana \\ ${ }^{4}$ Department of Pharmacology and Toxicology, \\ School of Pharmacy, University of Ghana, Legon, Accra, Ghana \\ ${ }^{5}$ Department of Chemistry, Faculty of Science, University of Cape Coast, Cape Coast, Ghana
}

\begin{abstract}
Problem statement: Gastrointestinal ulcers account significantly for morbidity and mortality in Ghana. The study therefore investigated the gastroprotective effect of an ethanolic root bark extract of Zanthoxylum zanthxyloides and its safety for us. Approach: Gastric ulceration was induced in Sprague-Dawley rats with Indomethacin $\left(25 \mathrm{mg} \mathrm{kg}^{-1}\right.$, p.o) and was treated with 150,250 , or $500 \mathrm{mg} \mathrm{kg}^{-1}$ of the extract, or $20 \mathrm{mg} \mathrm{kg}^{-1}$ Esomeprazole. The number of ulcers per stomach, Ulcerative Index and Curative Ratio were determined. A histological study of the gastric mucosa was also performed. The extract's effect on an isolated guinea-pig ileum preparation was investigated to elucidate its possible mechanism of action. Safety assessments involving, organ weight to body weight ratio determination, hematological analysis and liver function tests were performed. Results: The extract significantly decreased $(\mathrm{p} \leq 0.001)$ the number of ulcers per stomach and the Ulcerative Index (similar to Esomeprazole) and significantly increased $(\mathrm{p} \leq 0.001)$ the Curative Ratio in a dose-dependent manner. It completely corrected the architectural distortions caused by gastric ulceration and inhibited significantly $(\mathrm{p} \leq 0.001)$ the contractile responses of the isolated guinea-pig ileum to Acetylcholine, Nicotine and Histamine in a manner comparable to reference antagonists. The extract had no significant effect $(\mathrm{p}>0.05)$ on organ weight to body ratio and hematological profile. Plasma levels of Alanine transaminase and Alkaline phosphatase decreased significantly $(\mathrm{p} \leq 0.001)$ in extract and Esomeprazole-treated ulcerated rats. Levels of Gamma-glutamyl transferase, Total bilirubin (direct and indirect) however increased significantly ( $\mathrm{p} \leq 0.01-0.001)$. Conclusion/Recommendations: Per the findings, the ethanolic root bark extract of Zanthoxylum zanthoxyloides has gastroprotective effect in Sprague-Dawley rats working possibly via antimuscarinic or antihistaminic mechanism. It however has a potential of causing cholestasis hence liver function should be monitored.
\end{abstract}

Key words: Acetylcholine, Esomeprazole, Antimuscarinic, Antihistaminic, Gastric ulcer, Curative Ratio (CR), Ulcer Index (UI), White Blood Cell count (WBC), Red Blood Cell Count (RBC)

INTRODUCTION

Gastrointestinal ulcers accounts significantly for morbidity and mortality in developing parts of the world (Sharma et al., 2009; El-Sayed et al., 2012) probably because of the prevalence of Helicobacter pylori infections as a result of overcrowding, poor sanitation, poor water supply and poor socioeconomic

Corresponding Author: George Asumeng Koffuor, Department of Pharmacology, Faculty of Pharmacy and Pharmaceutical Sciences, Kwame Nkrumah University of Science and Technology, Kumasi, Ghana. 
conditions (Vítor and Vale, 2011). Diagnosis and treatment of ulcers lags behind in developing countries compared to advanced nations because of medically related technological gaps such as fibreoptic endoscopy and costs of test and medications which are cardinal in the effective management of ulcerative disorders.

Although there are several conventional antiulcer drugs used in treating gastrointestinal tract disorders, particularly gastric, peptic and duodenal ulcers; these drugs are not in most cases affordable to the ordinary individual giving their high cost and worse of all they come with adverse effects such as arrhythmias, impotence, gynaecomastia and haematopoietic changes (Mota et al., 2009). In view of this, there is the need to seek alternative drugs which are affordable, relatively safe, readily available and acceptable by the majority of the population. Globally, herbs are staging a comeback and herbal renaissance is happening all over (Chinthana and Ananthi, 2012). Many developing countries of the world are endowed with vast resources of natural products including medicinal plants which have been used as remedy for various disease conditions. It has been recorded that over three-quarters of the world population relies mainly on plants and plant extracts for healthcare. In China and India for example, drugs derived from plants constitute as much as $80 \%$ (Chinthana and Ananthi, 2012).

In Ghana, Zanthoxylum zanthxyloides (Lam) Waterm, commonly known as candle wood has been used traditionally to treat gastric and duodenal ulcers by some tribes (Irvine, 1961). Earlier work done on this plant indicates that it has analgesic, antihypertensive, antipyretic and diaphoretic properties (PORSPI, 1992).

Although herbal medicines have been extensively used in developed countries with the claim that they are natural and relatively safe compared to other forms of medicine (Riaz et al., 2010), harm from these medicines could occur. In this study therefore, the gastroprotective activity of Zanthoxylum zanthoxyloides as well as its safety for use was investigated.

\section{MATERIALS AND METHODS}

Collection, identification and authentication of plant: The root bark of Zanthoxylum zanthoxyloides was collected in December, 2011 from North Ola, a suburb of the Cape Coast Metropolis in the Central Region of Ghana. the plant part was identified and authenticated by Mr. Francis Otoo, the Curator at the herbarium unit, School of Biological Sciences, University of Cape Coast, where a voucher specimen (SBS/UCC/H261) was deposited.
Preparation of Zanthoxylum zanthoxyloides root bark extract: The root bark of Zanthoxylum zanthoxyloides was carefully removed, washed and sundried. The dried root bark was powdered using a hammer mill (Polymix Micro Hammer Cutter Mill, Glen Mills Inc, USA). A $1.075 \mathrm{~kg}$ quantity of the powder was defatted with $7 \mathrm{~L}$ of petroleum ether $(60-$ $80^{\circ} \mathrm{C}$ ) and soxhlet extracted with 6 litres of $95 \%$ ethanol in an soxhlet apparatus (L3 Soxlet extractor, Ergotech Soxhlet Apparatus Co, UK). A $200 \mathrm{~mL}$ quantity of the extract was condensed under low temperature and pressure using a rotor evaporator (Rotavapor R-210, Buchi, Switzerland) and dried in a hot air oven (Oven 300 plus series, Gallenkamp, England) maintained at a $40^{\circ} \mathrm{C}$ for $24 \mathrm{~h}$ to yield $42.5 \mathrm{~g}$ (Percentage yield: $3.95 \%$ ) of the dried extract which was named EZZ and will be referred to as such in this study.

Phytochemical screening: Screening was performed on EZZ to ascertain the presence of phytochemicals using standard procedures described by Kujur et al. (2010) and Kyei et al. (2012).

Experimental animals: Six-week old male albino rats $(150-210 \mathrm{~g})$ purchased from the Centre for Scientific Research into Plant Medicine (CSIRPM), MampongAkwapim, Ghana, were maintained in the Animal House of the School of Biological Sciences, University of Cape Coast, Ghana. The animals were housed in polyacrylic cages $(34 \times 47 \times 18 \mathrm{~cm})$ with soft wood shaving as bedding, under ambient laboratory conditions (temperature $25 \pm 2^{\circ} \mathrm{C}$, relative humidity 60 $70 \%$ and normal light-dark cycle). They were fed with normal commercial pellet diet (GAFCO, Tema, Ghana) and water ad libitum. All procedures and techniques used in these studies were in accordance with the National Institute of Health for the Care and Use of Laboratory Animals (NIH, Department of Health and Human Services publication no. 85-23, revised 1985). The protocols for the study were approved by the Departmental Ethics Committee.

Drugs and chemicals: Indomethacin (Letap Pharmaceuticals Ltd, Accra, Ghana), was used to induce ulcer in rats. Esomeprazole (AstraZeneca Pharmaceuticals, USA), a proton pump inhibitor, was the reference anti-ulcer drug. Acetylcholine bromide, Nicotine and Histamine diphosphate and Atropine, Hexamethonium and Mepyramine (May and Baker Ltd, Dagenham, England) were agonists and their reference antagonist respectively used on the isolated guinea-pig ileum for investigating the site of action of EZZ. 
Induction of gastric ulceration: Five albino rats were fasted for $24 \mathrm{~h}$ but had access to water. They were then given $25 \mathrm{mg} \mathrm{kg}^{-1}$ Indomethacin per os. After $6 \mathrm{~h}$ they were sacrificed and their stomachs removed. Each stomach was dissected along the greater curvature, the content removed and washed with normal saline. The appearance of ulcerative lesions was an indication of the formation of gastric ulcer.

Effect of EZZ on gastric ulcer formation: Experimental animals (fasted for $24 \mathrm{~h}$ ) were put into six groups of five. Group I (control) was given distilled water. Group II was given $250 \mathrm{mg} \mathrm{kg}^{-1}$ EZZ. In Groups III-V, gastric ulceration was induced and animals were treated with 150, 250, or $500 \mathrm{mg} \mathrm{kg}^{-1}$ EZZ after $6 \mathrm{~h}$. In Group VI gastric ulceration was induced and animals were treated with $20 \mathrm{mg} \mathrm{kg}^{-1}$ Esomeprazole after $6 \mathrm{~h}$. Drug treatment in all groups continued for 14 days. Rats were sacrificed and their stomach removed and examined for ulcerative lesions. The number of lesions in the stomachs of rats in each group was determined. The maximum length of each lesion (in millimeters) was determined and the sum of the lengths of all lesions in each stomach was expressed as the Ulcerative Index (UI) (Sivaraman and Muralidharan, 2010). The Curative Ratio (CR), expressed in percentage, was determined for each group using the formula: $\mathrm{CR}(\%)=$ (UI of Control-UI of treatment)/UI of Control $\times 100$. The stomachs were then fixed in $4 \%$ phosphatebuffered paraformaldehyde for histological studies at the Komfo Anokye Teaching Hospital, Kumasi, Ghana.

Determination of site of action of EZZ: A guinea-pig ileum was isolated and mounted in Tyrode physiological solution in a Harvard tissue bath (Harvard Apparatus Ltd, Kent, UK) as described by Koffuor et al. (2012). The baseline responses were recorded by means of a pendular lever system with the frontal writing point moving on a white paper wound around the cylinder (30 cm diameter) of a Harvard kymograph (Harvard Apparatus Ltd, Kent, UK) revolving at a rate of $4 \mathrm{~mm}$ per minute. Various concentrations of Acetylcholine and EZZ were applied in a preliminary test on an isolated guinea-pig ilium preparation to establish its intrinsic activity. It was established that EZZ had no contractile effect hence could be an antagonist drug. Subsequently, Acetylcholine $\left(1 \times 10^{-4}\right.$ $\left.1.3 \times 10^{-2} \mathrm{mg} \mathrm{mL}{ }^{-1}\right)$, Nicotine $\left(8 \times 10^{-4}-1.3 \times 10^{-2} \mathrm{mg}\right.$ $\left.\mathrm{mL}^{-1}\right)$ and Histamine $\left(1 \times 10^{-4}-6.4 \times 10^{-3} \mathrm{mg} \mathrm{mL}^{-1}\right)$ were applied on the guinea-pig ileum and the contractile responses recorded using a 3 minute time cycle and a $30 \mathrm{sec}$ contact time. Equipotent doses of Nicotine $\left(6.4 \times 10^{-3} \mathrm{mg} \mathrm{mL}^{-1}\right)$ and Histamine $\left(3.2 \times 10^{-3} \mathrm{mg} \mathrm{mL}^{-1}\right)$ giving responses similar to $75-80 \%$ the maximum response to Acetylcholine $\left(1.6 \times 10^{-3} \mathrm{mg} \mathrm{mL}^{-1}\right)$ were selected and matched. These submaximal doses were matched again in the presence of Hexamethonium $\left(5 \times 10^{-2} \mathrm{mg} \mathrm{mL}^{-1}\right)$, Atropine $\left(5 \times 10^{-6} \mathrm{mg} \mathrm{mL}^{-1}\right)$, Mepyramine $\left(2 \times 10^{-1} \mathrm{mg} \mathrm{mL}^{-1}\right)$ and EZZ $\left(3 \times 10^{-1} \mathrm{mg}\right.$ $\left.\mathrm{mL}^{-1}\right)$. The percentage inhibition of agonist response caused by the reference antagonist drugs and EZZ were computed and recorded. The procedure was repeated four times.

Organ weight to body weight ratio: After the 14 day treatment period, kidneys, lungs, hearts and livers of the animals were harvested and weighed. The organ weights to body weight ratios for the various organs were determined.

Hematological analysis: After the 14-day treatment period, bloods from sacrificed rats were collected into MediPlus K3 EDTA tubes (Sunphoria Co. Ltd., Taiwan) for hematological analysis. Red Blood Cell Count (RBC), White Blood Cell count (WBC), Hemoglobin Concentration (HB) and platelet counts (PLT) were estimated using a hematological analyzer (ABX Pentra 60, Horiba ABX, USA).

Liver function tests: After the 14 day treatment period, bloods from sacrificed rats were collected into plain tubes were allowed to stay undisturbed for 45 minutes to clotting. The clotted samples were spanned at $3000 \mathrm{rpm}$ for 15 minutes in a centrifuge (Nuve, NF 200; Turkey). Plasma obtained from the samples were transferred into sample tubes and labeled. Plasma levels of Aspartate Aminotransferase (AST), Alanine aminotransferase (ALT), Alkaline Phosphatase (ALP), Gamma-Glutamyl Transferase (GGT), Total Bilirubin (TBIL) and Direct Bilirubin (DBIL) were determined using appropriate working reagents (Fortress, Fortress Diagnostics, UK) a semi-automated chemistry analyzer (URIT 810, Guangzhou Shihai Medical Equipment Co., Ltd, China).

\section{RESULTS}

Phytochemical screening: Phytochemical screening of the EZZ revealed the presence of alkaloids, tannins, saponins, terpenoids and flavonoids.

Effect of EZZ on gastric ulcer formation: The number of ulcers per stomach and therefore UI in the ulcer induced group was high. The extract significantly $(\mathrm{p} \leq 0.001)$ and dose dependently decreased; the number of ulcers per stomach in each group and UI similar to Esomeprazole, a proton pump inhibitor. CR also increased very significantly $(\mathrm{p} \leq 0.001)$ in a dose-dependent manner (Table 1$)$. 
Am. J. Pharm. \& Toxicol., 7 (2): 73-80, 2012

Table 1: The number of ulcers formed, the Ulcerative Index (UI) and the Curative Ratio (CR) for 14-day EZZ and Esomeprazole -treated ulcerated rats and ulcerated but untreated rats

\begin{tabular}{|c|c|c|c|}
\hline Treatments & $\begin{array}{l}\text { Number of } \\
\text { ulcers/stomach/group }\end{array}$ & $\begin{array}{l}\text { Ulcerative } \\
\text { Index (mm) }\end{array}$ & $\begin{array}{l}\text { Curative } \\
\text { Ratio }(\%)\end{array}$ \\
\hline Control & $4.0 \pm 0.31$ & $8.46 \pm 0.67$ & $0.0 \pm 0.00$ \\
\hline EZZ $250 \mathrm{mg} \mathrm{kg}^{-1 \text { a }}$ & $0.0 \pm 0.0$ & $0.0 \pm 0.00$ & \\
\hline EZZ $150 \mathrm{mg} \mathrm{kg}^{-1 \mathrm{~b}}$ & $3.2 \pm 0.37 * *$ & $5.3 \pm 0.68 * * *$ & $35.33 \pm 1.36 * * *$ \\
\hline $\mathrm{EZZ} 250 \mathrm{mg} \mathrm{kg}^{-1 \mathrm{~b}}$ & $1.4 \pm 0.25 * * *$ & $2.28 \pm 0.25 * * *$ & $71.42 \pm 3.55 * * *$ \\
\hline EZZ $500 \mathrm{mg} \mathrm{kg}^{-1 \mathrm{~b}}$ & $0.4 \pm 0.24 * * *$ & $1.16 \pm 0.23 * * *$ & $85.30 \pm 4.05 * * *$ \\
\hline Esomeprazole $20 \mathrm{mg} \mathrm{kg}^{-1 \mathrm{~b}}$ & $0.8 \pm 0.44 * * *$ & $1.40 \pm 0.19$ *** & $67.18 \pm 3.60 * * *$ \\
\hline
\end{tabular}

Table 2: Photomicrographs of the gastric mucosa of normal, ulcerated and ulcerated with EZZ and Esomeprazole treatment for 14 days in Sprague-Dawley rats

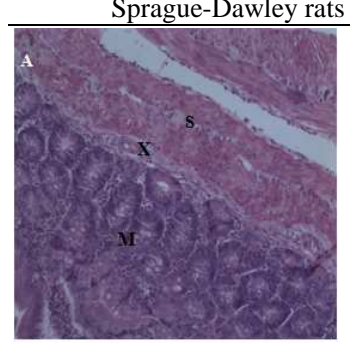

Plate A: Normal arrangement of cells in the walls of the gastric mucosa $(\mathrm{M})$, lamina propria (X) and sub-mucosal (S) layers in a non-ulcerated rat

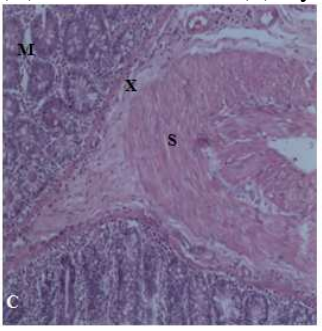

Plate C: Effect of EZZ (500 $\mathrm{mg} \mathrm{kg}^{-1}$ ) on gastric mucosal lesions induced by Indomethacin in rats. There is a total correction of the architectural distortions in the layers $\mathrm{M}, \mathrm{X}$ and $\mathrm{S}$ (compared to Plate B)

Haematoxylin and Eosin (H and E) stained, Magnification: 40X

Histological studies: Both EZZ and Esomeprazole completely corrected the architectural distortions caused by Indomethacin induced gastric ulceration (Table 2).

Determination of site of action of EZZ: EZZ significantly $(\mathrm{p} \leq 0.001)$ inhibited the contractile responses of the isolated guinea - pig ileum preparation to Acetylcholine, Nicotine and Histamine. Its effect was comparable to that observed for Atropine, Hexamethonium and Mepyramine, the standard antagonists to the agonists used (Table 3).

Cage side observations: Administration of the EZZ caused reduction in the intake of water and food. Rats clustered at the corners of cages after ulceration. This effect was however abolished in the Esomeprazole

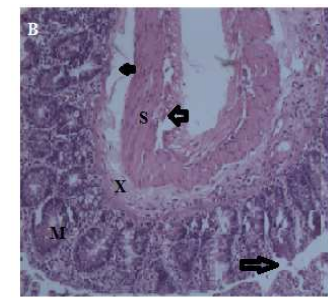

Plate B: Gross appearances of hemorrhagic gastric mucosal lesions(shown by the arrows) in ulcerated rats

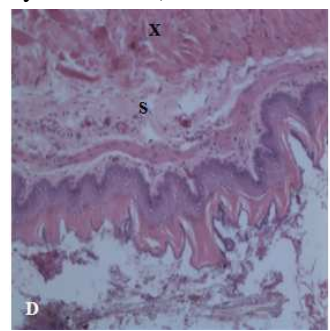

Plate D: Effect of Esomeprazole (20 $\left.\mathrm{mg} \mathrm{kg}^{-1}\right)$ showing an enhanced correction of the architectural distortions created by Indomethacin (compared to Plate B) treated and the $500 \mathrm{mg} \mathrm{kg}^{-1}$ EZZ treated group after the fourth day of treatment.

Organ weight to body weight ratio: There were no significant differences in the organ weight to body ratios of the liver, heart, lungs and kidney between the EZZ-treated groups and that of the control group (Table $4)$.

Haematological analysis: RBCs increased significantly $(p \leq 0.001)$; likewise HB $(p \leq 0.05)$; in $\mathrm{EZZ}$ and Esomeprazole-treated ulcerated rats. PLT also increased significantly $(p \leq 0.001)$ in all treated ulcerated rats. However, WBCs decreased significantly $(\mathrm{p} \leq 0.05)$ in the ulcerated rats receiving treatment. Rats which were not ulcerated but were receiving $250 \mathrm{mg} \mathrm{kg}^{-1}$ EZZ had significant increments in WBC, RBC and $\mathrm{HB}$ (Table 5). 
Am. J. Pharm. \& Toxicol., 7 (2): 73-80, 2012

Table 3: The inhibitory effect (\%) of Atropine, Hexamethonim, Mepyramine and EZZ on the contractile effect of Acetylcholine, Nicotine and Histamine on the isolated guinea-pig ileum preparation

\begin{tabular}{|c|c|c|c|}
\hline \multirow[b]{2}{*}{ Antagonist } & \multicolumn{3}{|c|}{ Percentage inhibition of Agonist effect by Antagonist } \\
\hline & Acetylcholine & Nicotine & Histamine \\
\hline Atropine $\left(5 \times 10^{-6} \mathrm{mg} \mathrm{mL}^{-1}\right)$ & $72.6 \pm 0.96 * * *$ & $3.0 \pm 0.58$ & $3.0 \pm 0.91$ \\
\hline Hexamethonium $\left(5 \times 10^{-2} \mathrm{mg} \mathrm{mL}^{-1}\right)$ & $2.3 \pm 0.85$ & $86.2 \pm 1.0 * * *$ & $1.25 \pm 0.75$ \\
\hline Mepyramine $\left(2 \times 10^{-1} \mathrm{mg} \mathrm{mL}^{-1}\right)$ & $2.3 \pm 0.63$ & $3.8 \pm 0.85$ & $65.7 \pm 0.12 * * *$ \\
\hline $\operatorname{EZZ~}\left(3 \times 10^{-1} \mathrm{mg} \mathrm{mL}^{-1}\right)$ & $65.8 \pm 1.0 * * *$ & $45.4 \pm 0.77 * *$ & $60.1 \pm 0.001 * * *$ \\
\hline
\end{tabular}

Values are mean \pm SEM $(n=5)$. Significant differences between the percentage inhibitions caused by the antagonists and the minimum inhibition possible determined using One-Way Analysis of variance followed by Dunnet's Multiple Comparison's Test. ** implies $\mathrm{p} \leq 0.01$; *** implies $\mathrm{p} \leq 0.001$

Table 4: Organ Weight to Body Weight Ratio calculated of controls and ulcerated rats treated with EZZ and Esomeprazole for 14 day

\begin{tabular}{|c|c|c|c|c|}
\hline \multirow[b]{2}{*}{ Groups } & \multicolumn{4}{|c|}{ Organ weight to body weight ratio } \\
\hline & Liver & Heart & Lungs & Kidney \\
\hline Control & $0.038 \pm 0.002$ & $0.006 \pm 0.011$ & $0.014 \pm 0.002$ & $0.010 \pm 0.00$ \\
\hline $\operatorname{EZZ}\left(250 \mathrm{mg} \mathrm{kg}^{-1}\right)^{\mathrm{a}}$ & $0.038 \pm 0.002$ & $0.004 \pm 0.025$ & $0.014 \pm 0.002$ & $0.010 \pm 0.00$ \\
\hline $\operatorname{EZZ~}\left(150 \mathrm{mg} \mathrm{kg}^{-1}\right)^{\mathrm{b}}$ & $0.040 \pm 0.000$ & $0.006 \pm 0.025$ & $0.014 \pm 0.002$ & $0.010 \pm 0.00$ \\
\hline $\operatorname{EZZ}\left(250 \mathrm{mg} \mathrm{kg}^{-1}\right)^{\mathrm{b}}$ & $0.040 \pm 0.000$ & $0.008 \pm 0.002$ & $0.014 \pm 0.000$ & $0.010 \pm 0.00$ \\
\hline $\operatorname{EZZ}\left(500 \mathrm{mg} \mathrm{kg}^{-1}\right)^{\mathrm{b}}$ & $0.040 \pm 0.000$ & $0.006 \pm 0.002$ & $0.018 \pm 0.002$ & $0.010 \pm 0.00$ \\
\hline Esomeprazole $\left(20 \mathrm{mg} \mathrm{kg}^{-1}\right)^{\mathrm{b}}$ & $0.042 \pm 0.002$ & $0.006 \pm 0.002$ & $0.020 \pm 0.003$ & $0.010 \pm 0.00$ \\
\hline
\end{tabular}

Values are mean $\pm \operatorname{SEM}(n=5) .{ }^{a}$ ulceration was not induced, ${ }^{\mathrm{b}}$ ulceration was induced

Table 5: Heamatological profile parameters measured of controls and ulcerated rats treated with EZZ and Esomeprazole for 14 days

\begin{tabular}{lllll}
\hline & WBC $\left(\times 10^{9} / \mathrm{L}\right)$ & $\mathrm{RBC}\left(\times 10^{9} / \mathrm{L}\right)$ & $\mathrm{HB}(\mathrm{g} / \mathrm{dL})$ & PLT $\left(\times 10^{9} / \mathrm{L}\right)$ \\
\hline Control & $8.40 \pm 0.68$ & $4.19 \pm 0.34$ & $11.30 \pm 0.68$ & $496.6 \pm 59.28$ \\
$\mathrm{EZZ}\left(250 \mathrm{mg} \mathrm{kg}^{-1}\right)$ & $10.74 \pm 0.61^{* * *}$ & $5.7 \pm 0.09^{* * *}$ & $14.02 \pm 0.33^{* * *}$ & $489.6 \pm 61.03 \mathrm{~ns}$ \\
$\mathrm{EZZ}\left(150 \mathrm{mg} \mathrm{kg}^{-1}\right)^{\mathrm{b}}$ & $7.76 \pm 0.45 \mathrm{~ns}$ & $5.23 \pm 0.06^{* * *}$ & $12.22 \pm 0.77 *$ & $797.0 \pm 54.28^{* * *}$ \\
$\mathrm{EZZ}\left(250 \mathrm{mg} \mathrm{kg}^{-1}\right)^{\mathrm{b}}$ & $7.14 \pm 0.09 \dagger \dagger$ & $5.63 \pm 0.02^{* * *}$ & $12.86 \pm 0.14^{*}$ & $807.0 \pm 76.00^{* * *}$ \\
$\mathrm{EZZ}\left(500 \mathrm{mg} \mathrm{kg}^{-1}\right)^{\mathrm{b}}$ & $7.34 \pm 0.19 \dagger \dagger$ & $5.34 \pm 0.16^{* * *}$ & $12.32 \pm 0.11^{*}$ & $868.0 \pm 50.93^{* * *}$ \\
Esomeprazole $\left(20 \mathrm{mg} \mathrm{kg}^{-1}\right)^{\mathrm{b}}$ & $7.30 \pm 0.61 \dagger \dagger$ & $5.57 \pm 0.46^{* * *}$ & $12.74 \pm 0.82^{*}$ & $569.4 \pm 87.52 \mathrm{~ns}$ \\
\hline
\end{tabular}

Values are mean \pm SEM $(n=5),{ }^{a}$ ulceration was not induced, ${ }^{b}$ ulceration was induced. Significant differences between the ulcerated but treated groups and the control were determined using One-Way Analysis of variance followed by Dunnet's Multiple Comparison's Test. For significant increments: $n s$ implies $p>0.05$; * implies $\mathrm{p} \leq 0.05$; *** implies $\mathrm{p} \leq 0.001$. For significant decrements: $n$ s imply $\mathrm{p}>0.05$; $\dagger$ implies $\mathrm{p} \leq 0.05$; $\dagger \dagger$ implies $\mathrm{p} \leq 0.01$

Table 6: Liver function test parameters measured of controls and ulcerated rats treated with EZZ and Esomeprazole for 14 days EZZ Treatment

\begin{tabular}{lllllll} 
Parameters & Control & $(250 \mathrm{mg} \mathrm{kg})$ & $\left(150 \mathrm{mg} \mathrm{kg}^{-1}\right)^{\mathrm{b}}$ & $\left(250 \mathrm{mg} \mathrm{k}^{-1}\right)^{\mathrm{b}}$ & $\left(500 \mathrm{mg} \mathrm{kg}^{-1}\right)^{\mathrm{b}}$ & $\left(20 \mathrm{mg} \mathrm{kg}^{-1}\right)^{\mathrm{b}}$ \\
\hline AST $(\mathrm{U} / \mathrm{L})$ & $9.90 \pm 2.31$ & $4.91 \pm 0.67 \dagger \dagger \dagger$ & $10.69 \pm 1.2 \mathrm{~ns}$ & $6.35 \pm 0.04 \dagger \dagger \dagger$ & $5.6 \pm 1.22 \dagger \dagger \dagger$ & $6.9 \pm 1.18 \dagger \dagger$ \\
ALT $(\mathrm{U} / \mathrm{L})$ & $151.64 \pm 5.62$ & $172.50 \pm 14.6 \mathrm{~ns}$ & $7.52 \pm 0.08 \dagger \dagger \dagger$ & $5.24 \pm 0.02 \dagger \dagger \dagger$ & $2.86 \pm 0.32 \dagger \dagger \dagger$ & $8.08 \pm 0.17 \dagger \dagger \dagger$ \\
ALP $(\mathrm{U} / \mathrm{L})$ & $1129.9 \pm 297.5$ & $861.2 \pm 212.2 \mathrm{~ns}$ & $4.288 \pm 0.05 \dagger \dagger \dagger$ & $3.26 \pm 0.14 \dagger \dagger \dagger$ & $2.64 \pm 0.04 \dagger \dagger \dagger$ & $3.6 \pm 0.22 \dagger \dagger \dagger$ \\
GGT $(\mathrm{U} / \mathrm{L})$ & $3.44 \pm 1.65$ & $4.72 \pm 2.30 \mathrm{~ns}$ & $20.26 \pm 0.05 * * *$ & $19.98 \pm 0.06 * * *$ & $20.0 \pm 1.41 * * *$ & $18.0 \pm 1.14 * * *$ \\
TBIL $(\mu \mathrm{mol} / \mathrm{L})$ & $0.44 \pm 0.05$ & $0.69 \pm 0.16 \mathrm{~ns}$ & $3.69 \pm 0.06 * * *$ & $3.61 \pm 0.00 * * *$ & $3.86 \pm 0.09 * * *$ & $4.6 \pm 0.37 * * *$ \\
DBIL $(\mu \mathrm{mol} / \mathrm{L})$ & $0.17 \pm 0.92$ & $0.16 \pm 0.24 \mathrm{~ns}$ & $2.42 \pm 0.22 * * *$ & $2.26 \pm 0.04 * * *$ & $2.70 \pm 0.26 * * *$ & $3.43 \pm 0.21 * * *$ \\
\hline
\end{tabular}

Values are mean \pm SEM $(\mathrm{n}=5),{ }^{a}$ ulceration was not induced, ${ }^{\mathrm{b}}$ ulceration was induced. Significant differences between the ulcerated but treated groups and the control were determined using One-Way Analysis of Variance followed by Dunnet's Multiple Comparison's Test. For significant increments: ns implies $\mathrm{p}>0.05$; *** implies $\mathrm{p} \leq 0.001$. For significant decrements: $n s$ implies $\mathrm{p}>0.05$; $\dagger \dagger$ implies $\mathrm{p} \leq 0.01 ; \dagger \dagger \dagger$ implies $\mathrm{p} \leq 0.001$. Aspartate aminotransferase (AST), Alanine aminotransferase (ALT), Alkaline phosphatase (ALP), Gamma-Glutamyltransferase (GGT), Total bilirubin (TBIL) and Direct Bilirubin (DBIL)

Liver function tests: Plasma levels of ALT and ALP decreased significantly $(p \leq 0.001)$ and dose-dependently in ulcerated animals treated with EZZ. Levels of GGT, TBIL and DBIL also increased significantly $(\mathrm{p} \leq 0.001)$; though not dose dependently. A similar trend was observed in the esomeprazole-treated group.
With the exception of the ulcerated group which received $150 \mathrm{mg} \mathrm{kg}$ EZZ there was significant decrease $(\mathrm{p} \leq 0.01-0.001)$ in plasma AST levels for the EZZ and Esomeprazole-treated groups compared to the controls with values comparable to the nonulcerated rats treated with $250 \mathrm{mg} \mathrm{kg}^{-1}$ EZZ (Table 6). 
Am. J. Pharm. \& Toxicol., 7 (2): 73-80, 2012

\section{DISCUSSION}

Indomethacin-induced gastric ulceration is a suitable model for investigating the gastroprotective effects of drugs. Indomethacin is a Cyclooxygenase-1 (COX-1) inhibitor which acts to prevent the biosynthesis of prostaglandins. Prostaglandin E2 together with mucus and bicarbonate ions provide protection to the gastrointestinal lining against the actions of gastric acid and proteolytic enzymes. Indomethacin, therefore induce ulceration by disruption of protection offered by prostaglandins to the gastric mucosa.

Although recent advances in our understanding have highlighted the multi-factorial pathogenesis of peptic ulcers, gastric acid secretion is still recognized as a central component in ulcers. It is for this reason that, the main therapeutic effects of most conventional antiulcer drugs is targeted at neutralizing or control of gastric acid secretion by antacids, antihistaminics and proton pump inhibitors (Sumbul et al., 2011). The walls of the stomach contain parietal cells and their action is influenced by three chemical transmitters; Histamine Acetylcholine and Gastrin. The three transmitters work in concert to stimulate the parietal cells to produce hydrochloric acid. Overproduction of $\mathrm{HCl}$ by the parietal cells leads to hyperacidity of the stomach resulting in erosion of the mucous membrane and subsequently ulcer formation. EZZ effectively inhibited the contractile effects of Acetylcholine and Histamine on the isolated guinea-pig ileum, indicating how EZZ might have suppressed the role of acetylcholine and histamine (via antimuscarinic or antihistaminic activity) in gastric acid secretion at the cellular level and hence suppression of ulcer formation and development.

The histological studies conducted on the gastric mucosa confirmed healing of the distorted tissue layers (lesions or ulcers). The ulcerated but treated (with EZZ or Esomeprazole) gastric mucosa of the rats showed fewer lesions with significantly reduced diameters were seen i.e., a decreased UI with an increased CR particularly in the high dose EZZ (it effect was even better compared to the esomeprazole group).

Organ weights are widely accepted in the evaluation of test agent-associated toxicities (Sellers $e t$ al., 2007). The Society of Toxicologic Pathology recommends that organ weights be included routinely in toxicity studies for multidose drugs administered in durations from 7 days to 1 year (Sellers et al., 2007). The organ weight to bodyweight ratios of all the treated groups was not significantly different from that of the control group. This indicates that both EZZ and Esomeprazole had no effect on organ weight and therefore would possibly have no organ-related toxicity.
Results obtained after hematological studies do not reveal any toxic effect of EZZ on blood as similar effects were seen with Esomeprazole treatment. The decrease in WBCs in blood in the EZZ and Esomeprazole-treated ulcerated rats could possibly be due to migration of some of these cells from blood (leucocyte extravasation) into areas around the damaged mucosal tissue as part of innate immune response in the body's defense mechanism (Hyun et al., 2012). The decrease in $\mathrm{RBC}$ and $\mathrm{HB}$ in blood could possibly be the result of blood lost from ulcers developed in the stomach (Seibert, 2012).

To ascertain the integrity and functionality of the liver, plasma ALT and AST levels are often compared to plasma ALP, Total protein and Total bilirubin. In the ulcerated rats that were being treated with EZZ and Esomeprazole, there were reduction in the plasma levels of ALP, AST and ALT which may indicate that the treatment does not cause injury or damage to hepatocytes. Plasma ALP and ALT levels are elevated (as seen in the ulcerated rats) in inflammatory disorders of the bowel (gastroenteritis) and in malnutrition e.g. Alcohol ingestion that causes damage to the gastric mucosa results in the release of marker enzyme ALP into the blood (Borashan et al., 2009; Jothi et al., 2012), while administration of Phenylbutazone in Arabian horses caused gastric epithelium injury and elevated ALP, ALT, AST and GGT (Saeid and Ali, 2011). The extract and esomeprazole significantly reduced ALP levels compared to the untreated ulcerated rats implying mucosal reconstruction and regeneration of gastric tissue. A significant reduction in ALP level implies antiulcerogenic property (Srivastava et al., 2012).

It can thus be said that EZZ does not have the potential of causing liver injury or damaging hepatocytes (acute liver damage); which is seen by the rise in plasma ALT and/or AST levels (Koffuor et al., 2010). The extract and Esomeprazole treatment however possibly decreases the liver's functionality by decreasing its excretory ability which was evidently seen by a rise in GGT and Total Bilirubin (direct and indirect bilirubin). Increased levels of GGT may indicate in general that the liver is being damaged but does not specifically point to a condition that may be causing the injury. Increases in TBIL and DBIL may indicate problems with the liver, which are reflected as deficiencies in bilirubin metabolism (e.g., reduced hepatocyte uptake, impaired conjugation of bilirubin and reduced hepatocyte secretion of bilirubin). Elevation of direct bilirubin indicates that the liver is conjugating bilirubin normally, but is not able to excrete it possibly due to bile duct obstruction by gallstones. It has been documented that patients 
developed bland and somewhat prolonged cholestasis after only two weeks of $\mathrm{H}_{2}$-blocker therapy. Similar observation was also made in this study for Esomeprazole and EZZ treatment. It therefore implies that EZZ has the potential to cause cholestasis (interference with the livers excretory ability) and hence impair liver function. The similar adverse effect of causing cholestasis observed for both EZZ and esomeprazole could confirm the observation in this study that EZZ has antihistaminic effect.

The activity of the extract observed is due phytochemicals present. Preliminary screening revealed the presence of alkaloids, tannins, saponins, terpenoids and flavonoids affirming an earlier report by Adeniyi $e t$ al. (2010). Some alkaloids have been reported to have gastroprotective effects (Gadekar et al., 2010; Hariprasath et al., 2012; Nwidu and Nwafor, 2009). Tannins have also been reported to contribute immensely in gastroprotection (Dragana et al., 2009; Vasconcelos et al., 2010) while some saponins also protect the gut from ulcerogenic agents (Yoshikawa et al., 2008; Nwidu and Nwafor, 2009). A study conducted in Siqueira et al. (2012), had reported the role of terpinoids in the prevention of ulcer and the healing of existing ulcers. The role of flavonoids in gastroprotection cannot be over ruled (Mota et al., 2009; Hussaini et al., 2012).

\section{CONCLUSION}

The ethanolic root bark extract of Zanthoxylum zanthoxyloides has gastroprotective effect in Sprague-Dawley rats working possibly via antimuscarinic or antihistaminic mechanism. It however has a potential of causing cholestasis hence liver function should be monitored.

\section{REFERENCES}

Adeniyi, T.T., G.O. Ajayi, M. A. Akinsanya and T.M. Jaiyeola, 2010. Biochemical changes induced in rats by aqueous and ethanolic corm extracts of Zygotritonia croceae. Sci. Res. Essays, 5: 71-76.

Borashan, F.A., M. Ilkhanipoor, M. Hashemi and F. Farrokhi, 2009. Investigation the effects of curcumin on serum hepatic enzymes activity in a rheumatoid arthritis model. Elect. J. Biol., 4: 129133.

Chinthana, P. and T. Ananthi, 2012. Protective Effect of Solanum nigrum and Solanum trilobatum aqueous leaf extract on lead induced neurotoxicity in Albino mice. J. Chem. Pharm. Res, 4: 72-74.
Dragana, D., J.H. Snežana, T. Vanja, M. Goran and A. Ivana et al., 2009. Phytochemical analysis and gastroprotective activity of an olive leaf extract. J. Serb. Chem. Soc., 74: 367-377. DOI: 10.2298/JSC0904367D

El-Sayed, M.K., H. Amin and A. Al-Kaf, 2012. Antimicrobial, anti-oxidant and anti-ulcerogenic effects of shilajit on gastric ulcer in rats. Am. J. Biochem. Biotechnol., $\quad 8: \quad 26-39 . \quad$ DOI: 10.3844/ajbbsp.2012.26.39

Gadekar, R., P.K. Singour, P.K. Chaurasiya, R.S. Pawar and U.K. Patil, 2010. A potential of some medicinal plants as an antiulcer agents. Phcog Rev., 4: 136-46. DOI: 10.4103/0973-7847.70906

Hariprasath, L., J. Raman and R. Nanjian, 2012. Gastroprotective effect of Senecio candicans DC on experimental ulcer models. J. Ethnopharmacol, 140: 145-150. PMID: 22245753

Hussaini, J., N.A. Othman, M.A. Abdulla, N.A. Majid and H.M. Faroq et al., 2012. Gastroprotective effects of Dicranopteris linearis leaf extract against ethanol-induced gastric mucosal injury in rats. Sci. Res. Essays, 7: 1761-1767. DOI: 10.5897/SRE11.775

Hyun, M.Y., R. Sumagin, P.P. Sarangi, E. Lomakina and M.G. Overstreet et al., 2012. Uropod elongation is a common final step in leukocyte extravasation through inflamed vessels. JEM, 209: 1349-1362. DOI: $10.1084 / \mathrm{jem} .20111426$

Irvine, F.R., 1961. Woody Plants of Ghana: With Special Reference to their Uses. 1st Edn., Oxford, University Press, London, pp: 868.

Jothi, G., J. Radhika, M. Palani and K. Ganesh, 2012. Protective effect of Annona squamosa linn. leaf extract on $\mathrm{HCl}$-ethonal induced gastric ulcer in albino rats. Int. J. Pharm Pharm Sci., 4: 83-85.

Koffuor, G.A., A. Boye, P. Amoateng, E.O. Ameyaw and A.K. Abaitey, 2012. Investigating the site of action of an aqueous extract of heliotropium indicum linn (boraginaceae) on smooth muscles. Res. J. Pharmacol., 6: 12-19.

Koffuor, G.A., E. Woode, C. Obirikorang and E. Asiamah, 2010. Toxicity evaluation of a polyherbal antihypertensive mixture in Ghana. J. Pharmacy Allied Health Sci., 1: 34-38. DOI: 10.3923/jpahs.2011.34

Kujur, R.S., V. Singh, M. Ram, H.N. Yadava and K.K. Singh et al., 2010. Antidiabetic activity and phytochemical screening of crude extract of Stevia rebaudiana in alloxan-induced diabetic rats. Pharmacognosy Res., 2: 258-63. DOI: $10.4103 / 0974-8490.69128$ 
Kyei, S., G.A. Koffuor and J.N. Boampong, 2012. Antiarthritic effect of aqueous and ethanolic leaf extracts of Pistia stratiotes in adjuvant-induced arthritis in Sprague-Dawley rats. J. Exp. Pharmacol., 4: 41-51.

Mota, K.S.D., G.E.N. Dias, M.E.F. Pinto, A. LuizFerreira and A.R.M. Souza-Brito et al., 2009. Flavonoids with gastroprotective activity. Molecules, 14: 979-1012. DOI: 10.3390/molecules 14030979

Nwidu, L.L. and P.A. Nwafor, 2009. Gastroprotective effects of leaf extracts of Carpolobia lutea (Polygalaceae) G. Don. in rats. Afr. J. Biotechnol., 8: 012-019.

PORSPI, 1992. Ghana Herbal Pharmacopoeia. 1st Edn., Policy Research and Strategic Planning Institute, Accra, ISBN-10: 9964913257, pp: 205.

Riaz, A, R.A. Khan, S. Ahmed and S. Afroz, 2010. Assessment of acute toxicity and reproductive capability of a herbal combination. Pak. J. Pharm. Sci., 23: 291-294. PMID: 20566442

Saeid, S. and H. Ali, 2011. Phenylbutazone administration in arabian horses and its digestive and cardiac injuries (biochemical, hematological and endoscopic findings). Global Vet., 7: 512-517.

Seibert, A., 2012. Understanding ulcers. WebMD, LLC.

Sellers, R.S., D. Morton, B. Michael, N. Roome and J.K. Johnson et al., 2007. Society of toxicologic pathology position paper: Organ weight recommendations for toxicology studies. Toxicol. Pathol., 35: 751-755. DOI: 10.1080/01926230701595300

Sharma, S.K., D.K. Maharjan and P.B. Thapa, 2009. Hospital based analytic study of peptic ulcer disease in patients with dyspeptic symptoms. Kathmandu Univ. Med. J. (KUMJ)., 7: 135-138. PMID: 20071846
Siqueira, B.P.J., C.T. Menezes, J.P. Silva, D.P.D. Sousa and J.S. Batista, 2012. Antiulcer effect of epoxycarvone. Brazilian J. Pharm., 22: 144-149.

Sivaraman, D. and P. Muralidharan, 2010. Antiulcerogenic evaluation of root extract of Ficus hispida Linn. in aspirin ulcerated rats. Afr. J. Pharm. Pharmacol., 4: 79-82.

Srivastava, V., G. Mohan and A.H.M. Viswanathswamy, 2012. Protection of ethanol induced ulcers by sodium cromoglycate in albino rats. Ind. J. Pharm Educ. Res., 46: 32-36.

Sumbul, S., M.A. Ahmad, M. Asif and M. Akhta, 2011. Role of phenolic compounds in peptic ulcer: An overview. J. Pharm. Bioallied. Sci., 3: 361-367. DOI: $10.4103 / 0975-7406.84437$

Vasconcelos, P.C., M.A. Andreo, W. Vilegas, C.A. Hiruma-Lima and C.H. Pellizzon, 2010. Effect of Mouriri pusa tannins and flavonoids on prevention and treatment against experimental gastric ulcer. J Ethnopharmacol., 131: 146-53. PMID: 20600773

Vítor, J.M.B. and F.F. Vale, 2011. Alternative therapies for Helicobacter pylori: Probiotics and phytomedicine. FEMS Immunol. Med. Microbiol., 63: $153-164 . \quad$ DOI: $\quad 10.1111 / \mathrm{j} .1574-$ 695X.2011.00865.x

Yoshikawa, M., T. Wang, S. Sugimoto, S. Nakamura and A. Nagatomo et al., 2008. Functional saponins in tea flower (flower buds of Camellia sinensis): gastroprotective and hypoglycemic effects of floratheasaponins and qualitative and quantitative analysis using HPLC. Yakugaku Zasshi., 128: 141151. PMID: 18176066 